\title{
Pleurisy in Hemodialysis Patients: Epidemiological and Etiological Aspects at Donka National Hemodialysis Center
}

\author{
M. Traoré1*, F. Diakité1, M. S. Baldé1, I. Chérif1, M. Sidibé1, A. B. Bah¹, N. M. A. Nyaméni1, \\ M. L. T. Camara1, M. Camara1, M. K. Kanu' ${ }^{2}$ A. O. Bah1', M. L. Kaba1 \\ ${ }^{1}$ Department of Nephrology-Hemodialysis, Conakry, Guinea \\ ${ }^{2}$ Medical Care Clinic, Freetown, Sierra-Leone \\ Email: ^mousa11traore@gmail.com
}

How to cite this paper: Traoré, M., Diakité, F., Baldé, M.S., Chérif, I., Sidibé, M., Bah, A.B., Nyaméni, N.M.A., Camara, M.L.T., Camara, M., Kanu, M.K., Bah, A.O. and Kaba, M.L. (2021) Pleurisy in Hemodialysis Patients: Epidemiological and Etiological Aspects at Donka National Hemodialysis Center. Open Journal of Nephrology, 11, 1-8.

https://doi.org/10.4236/ojneph.2021.111001

Received: November 10, 2020

Accepted: January 26, 2021

Published: January 29, 2021

Copyright $\odot 2021$ by author(s) and Scientific Research Publishing Inc. This work is licensed under the Creative Commons Attribution International License (CC BY 4.0).

http://creativecommons.org/licenses/by/4.0/

\begin{abstract}
Introduction: Pleural effusion being a frequent complication in hemodialysis patients, its etiologies are diverse and the diagnosis is easy, based on clinical and radiological proofs. The main objective of this study was to describe the epidemiological and etiological profiles of pleurisy in hemodialysis patients at the National Hemodialysis Center of Donka National Hospital. Patients and methods: it was a retrospective, descriptive and analytical study that extended over a period of three years from January 1, 2017 to December 31, 2019. It concerned, among hemodialysis patients in the center during the study period, all those who had a confirmed pleurisy on chest $\mathrm{x}$-ray. The variables were epidemiological (based on frequency, sex and age), clinical (based on history of the disease, physical examination looking for a reduction or elimination of vesicular murmur) and paraclinical (mainly radiological). Results: Among 286 patients undergoing hemodialysis in our center, pleural effusion was diagnosed in 35 or $12.24 \%$. The average age of our patients was 52.22 years with ranges of 18 and 78 years. The sex ratio $\mathrm{M} / \mathrm{F}$ was 2.5 . Bilateral pleurisy was found in $51.43 \%$ of patients; unilateral right in $40 \%$ of cases and unilateral left in $8.57 \%$. We observed $68.57 \%$ citrus yellow fluid and $31.43 \%$ sero haematic fluid. The bacteriology of the pleural fluid was positive in $62.86 \%$ against $37.14 \%$ negative. $\mathrm{Tu}-$ mor, tuberculosis and non-specific bacterial etiologies have been encountered. Conclusion: Pleurisy is therefore a frequent complication in hemodialysis patients at Donka National Hemodialysis Center. Etiological research is a major step for better management of these patients. Improving the technical platform of the laboratories should be an important contribution to this stage.
\end{abstract}




\section{Keywords}

Pleurisy, Hemodialysis, Epidemiology, Etiologies

\section{Introduction}

Pleurisy is an inflammation of the pleural leaflets characterized by the appearance of exudative or transudative pleural effusion, which is the result of maladjustment in the balance between the accumulation of pleural fluid and its resorption [1].

This situation is often observed in hemodialysis populations with, according to the literature, a frequency of about $20 \%$ and uremia is one of its main etiologies [2]. Other common causes such as hypervolemia, congestive heart failure, coronary artery disease, tuberculosis, collagen vascular disease etc., are found [1].

However, with this etiological diversity, the limited access of populations to explorations and the plurality of mechanisms of appearance, pleurisy poses a major problem of etiological diagnosis [1] [2].

Thus, T. Bakirci et al. reported that pleural effusions due to hypervolemia occupied $61.5 \%$ of cases in hemodialysis patients in Turkey between 1990 and 2006, while tuberculous pleurisy represented $1.9 \%$ of cases in the same series [3].

Tuberculosis, favored by an unfavorable socio-economic level, is omnipresent in Africa, particularly in hemodialysis patients, in whom cellular immunity is weakened. In a longitudinal prospective study carried out in southern Senegal, Y. Kane et al. reported that GeneXpert confirmed tuberculosis involvement in 6 out of 7 possible cases (or $85.80 \%$ ), including 4 cases from pleural puncture fluid, in chronic hemodialysis patients [4]. According to T. Mesbahi et al., in Tunisia, $56 \%$ of tuberculosis diagnoses were retained in front of clinical and biological presumption associated with the radiological one, despite the negativity of the bacteriological and histological samples [5].

In Guinea, in our knowledge, no previous study has focused on this subject. Due to the increase in frequency of respiratory pathologies observed in our patients, we found the need to do this work, the objective of which was on the one hand to carry out an epidemiological study of pleurisy in our center, on the other hands, to determine the main etiologies.

\section{Patients and Methods}

It was a descriptive retrospective study that extended over a period of three years from January 01, 2017 to December 31, 2019 at the National Hemodialysis Center in Donka. We included all the patients followed in the center during the study period for their hemodialysis sessions, who had to develop pleurisy. Hemodialysis patients who did not develop pleurisy, as well as those who presented pleurisy but which were not explored, were not included.

Data was collected from hemodialysis follow-up medical records, dialysis 
notebooks and registers, pre-established survey sheets for this work.

Our variables were epidemiological (including frequency, sex, age), the clinical examination was done looking for signs in favor of pleural effusion, chest $\mathrm{x}$-ray for diagnostic confirmation and localization of the effusion, pleural fluid analysis and GeneXpert for etiological research.

We performed a frequency distribution for the qualitative variables and we calculated the mean and the standard deviation for the quantitative variables.

The information obtained was used for a purely scientific purpose and the confidentiality of each patient was respected.

\section{Results}

This descriptive retrospective study, carried out in our center over a period of 3 years, included, according to the criteria defined in methodology, 286 hemodialysis patients. The presence of pleurisy was confirmed on chest x-ray in 35 patients, or $12.24 \%$ of the sample. In 251 patients or $87.76 \%$, the diagnosis of pleurisy was negative.

Our patients were divided into age groups of 10 years. The most affected group was that of 50 - 59 years with 11 cases, or $31.43 \%$.

The average age was 52.22 years and the extremes ages were 18 and 78 years old.

We observed a male predominance on female. Respectively 25 , or $71.43 \%$ and 10 , or $28.57 \%$. The sex ratio $\mathrm{M} / \mathrm{F}$ was 2.5 .

The main initial nephropathy was mixed nephropathy with 16 cases or $45.71 \%$, followed by 9 cases of glomerular nephropathy or $25.71 \%$, then diabetic nephropathy at $14.29 \%$, vascular nephropathy $8.57 \%$ and $5.71 \%$ of chronic tubulointerstitial nephropathy.

About location of pleurisy on chest $\mathrm{x}$-ray, 18 patients had it bilaterally located, or $51.43 \%$. For 17 patients, or $48.57 \%$, it was unilaterally located.

Otherwise, nonspecific bacterial infections were the predominant etiology with 19 cases or $54.29 \%$. The other etiologies were in order tumor $37.14 \%$ and tuberculous $8.57 \%$.

Macroscopically, there were in majority 24 cases of yellow-citrus liquid, or $68.57 \%$ against $31.43 \%$ of the serohematic.

Microscopically, there was a predominance of exudate, 29 cases or $82.86 \% ; 13$ patients or $37.14 \%$ of cases were showing malignant cells; 22 cases of positive bacteriology or $62.86 \%$ have been found.

As for GeneXpert, it was positive in all the 3 cases of tuberculosis, or $8.57 \%$.

\section{Discussion}

This was a 3-years descriptive retrospective study carried out at the National Hemodialysis Center in Donka National Hospital. During this study period, we collected 286 files of hemodialysis patients. Among them, 35 patients or $12.24 \%$ had developed pleurisy (Table 1). This rate is different from the incidence found 
Table 1. Distribution of patients according to general characteristics.

\begin{tabular}{ccc}
\hline Parameters & Number & Percentage \\
\hline Frequency & 286 & 100 \\
Pleurisy (+) & 35 & 12.24 \\
Pleurisy (-) & 251 & 87.76 \\
Age & 35 & 100 \\
$18-28$ & 4 & 11.43 \\
$29-39$ & 2 & 5.71 \\
$40-49$ & 5 & 14.29 \\
$50-59$ & 11 & 31.43 \\
$60-69$ & 9 & 25.71 \\
$\geq 70$ & 4 & 11.43 \\
Sex & 35 & 100 \\
Male & 25 & 71.43 \\
Female & 10 & 28.57 \\
Sex ratio M/F & &
\end{tabular}

by T. Bakirci and al. in their work on "Pleurisy in long-term hemodialysis patients" between 1990 and 2006 in Turkey, during which work the incidence of pleurisy was $20.20 \%$ [3].

The high rate of pleurisy cases in our cohort could be explained, among other things, by the insufficient hemodialysis dose offered (twice four hours per week) and the non-compliance by patients with the recommendations on hydrosodium restriction.

In our study, the most represented age group was that of 50 - 59 years with 11 cases or $31.43 \%$.

The average age was 52.22 years with extremes of 18 and 78 years (Table 1 ). Our results are close to those of T. Bakirci and al. who found in their work an average age of $55.83 \pm 16.56$ years [3]

The explanation of this large proportion of elderly subjects on dialysis having pleurisy varies according to the studies and depends on various causes. Some authors believe that it's due to the fact that the age of patients starting dialysis has been increasing steadily in recent years (the median age is 71 years in France) [6]. Others explain it by the fact that heart failure, which is a frequent complication in dialysis patients, is a full-fledged etiology of pleurisy [7] [8].

We noted a male predominance with 25 cases (71.43\%) against 10 cases (28.57\%) for females. The sex ratio M/F was 2.5 (Table 1). These results are consistent with data in the literature according to which end-stage renal disease is two to three times more common in men than in women [6].

In our series, mixed nephropathy was the most common initial nephropathy (16 cases, or $45.71 \%$ ) followed by chronic glomerular nephropathy, then diabetic nephropathy with respectively 9 cases (25.71\%) and 5 cases (14.29\%) (Table 2). 
Table 2. Distribution of patients according to the initial nephropathy.

\begin{tabular}{ccc}
\hline Initial nephropathy & Number & Percentage \\
\hline Diabetic nephropathy & 5 & 14.29 \\
Chronic tubulointerstial nephropathy & 2 & 5.71 \\
Glomerular nephropathy & 9 & 25.71 \\
Mixed nephropathy & 16 & 45.71 \\
Vascular nephropathy & 3 & 8.57 \\
TOTAL & 35 & 100.00 \\
\hline
\end{tabular}

These results are different from those of Kouamé HY and al. on "Particularities of tuberculosis in chronic black African dialysis patients" [9] who, in 2011, found at the end of their study that the initial nephropathy was primarily vascular (42.8\%), diabetic (28.5\%) or associated with HIV (14.8\%). We have not found an explanation for this predominance of mixed kidney disease over other etiologies in our patients.

Our work identified bilateral pleurisy in 18 cases, i.e. 51.43\%, unilateral right in 14 cases, or $40 \%$, and unilateral left in 3 cases, or $8.57 \%$ (Table 3).

We observed 24 cases or $68.57 \%$ of citrus yellow fluid and 11 cases or $31.43 \%$ of serohematic fluid (Table 4). Our results are different from those of $\mathrm{H}$. Haddaoui and al. in Morocco [10], in their work published in 2018 on "Etiological profile of pleurisy at the Moulay Youssef Hospital", where they had observed that in $68 \%$ of cases the fluid was sero-fibrinous, in $15 \%$ it was serohematic and clear in $8 \%$ of cases. It should be noted that this work by $\mathrm{H}$. Haddaoui had been carried out in patients without renal insufficiency. The high level of citrus yellow fluid in our study could be explained by the fact that this aspect included many cases of both transudate and exudate.

The bacteriology of the pleural fluid was positive in 22 cases or $62.86 \%$ against 13 cases or $37.14 \%$ of negative (Table 4). The work of L. Najah et al. in Morocco in 2018 on "The bacteriological profile of purulent pleurisy" found a non-contributory bacteriology in $75 \%$ of cases [11]. By comparison, therefore, we had more cases of positive bacteriology than them with these 22 cases (62.86\%) in our study. These positivity cases involved both tuberculosis and non-specific germs.

In our study, with 3 patients, or $8.57 \%$ of cases, GeneXpert was positive (Table 4). Our results are lower than those of El Amrani M. et al. [12] in Morocco in 2016 , which found a frequency of $23 \%$ of tuberculosis cases diagnosed with GeneXpert in hemodialysis patients. This low frequency in our patients could be explained by the low use of GeneXpert due to the cost. Even so, since GeneXpert tested positive for all 3 cases of tuberculosis among our patients, this would be in agreement with the results of previous studies which showed that GeneXpert had a high potential to confirm the diagnosis of tuberculosis in chronic hemodialysis patients. In their work published in 2014, Steingart KR et al. noted a total sensitivity of $89 \%$ and a specificity of $99 \%$ for the detection of tuberculosis by GeneXpert 
Table 3. Distribution of patients according to the location of the pleurisy.

\begin{tabular}{cccc}
\hline Location of pleurisy & Number & Percentage \\
\hline Bilateral & 18 & 51.43 \\
Unilateral & 17 & 48.57 \\
& Right & 14 & 40 \\
& Left & 3 & 8.57 \\
Etiologies & & & \\
Non specific bacterial & 19 & 54.29 \\
Tuberculous & 3 & 8.57 \\
Tumor & 13 & 37.14 \\
\hline
\end{tabular}

Table 4. Distribution of patients according to the result of macroscopy and microscopy of pleural fluid.

\begin{tabular}{ccc}
\hline Macroscopy and microscopy of pleural fluid & Number & Frequency \\
\hline Pleural fluid & 24 & $68.57 \%$ \\
Citrus yellow & 11 & $31.43 \%$ \\
Serohematic & & \\
Light criteria: & 29 & $82.86 \%$ \\
Exudate & 6 & $17.14 \%$ \\
Transudate & & \\
Malignant cells: & 22 & $62.86 \%$ \\
No & 13 & $37.14 \%$ \\
Yes & 13 & $37.14 \%$ \\
Pleural bacteriology: & 22 & $62.86 \%$ \\
Negative & & $91.43 \%$ \\
Positive & 32 & $8.57 \%$ \\
Penexpert in pleural fluid: & 3 & \\
Negative & & \\
Positive & & \\
\hline & & \\
\hline
\end{tabular}

[13]. Moreover, in September 2010, the World Health Organization (WHO) strongly advocated for the rapid and large-scale implementation of GeneXpert [14].

Finally, let us point out that the poor keeping of certain patient files, the non-performance of certain paraclinical examinations were the main limitations of our study.

\section{Conclusion}

At the end of this study which focused on pleurisy in hemodialysis patients, it appears that pleurisy is frequent in these patients. The etiologies were: tumor, 
tuberculosis and nonspecific bacterial. Exudative pleural fluid was the most common. However, close monitoring and for future studies, taking into account therapeutic education for renal failure would help to prevent this complication.

\section{Conflicts of Interest}

The authors declare no conflicts of interest regarding the publication of this paper.

\section{References}

[1] Pastré, J., Roussel, S., Israël Biet, D. and Sanchez, O. (2015) Orientation diagnostique et mesures à prendre en cas d'épanchement pleural. La Revue de Médecine Interne, 36, 248-255. https://doi.org/10.1016/j.revmed.2014.10.360

[2] Rashid-Farokhi, F., Pourdowlat, G., Nikoonia, M.-R., Behzadnia, N., Kahkouee, S., Nassiri, A.-A. and Masjedi, M.-R. (2013) Pleurite urémique chez les patients hémodialysés chroniques. Bibliothèque nationale de medicine, 17, 94-100. https://doi.org/10.1111/j.1542-4758.2012.00722.x

[3] Bakirci, T., Sasak, G., Ozturk, S., Akcay, S., Sezer, S. and Haberal, M. (2007) Pleural Effusion in Long-Term Hemodialysis Patients. Transplantation Proceedings, 39, 889-891. https://doi.org/10.1016/j.transproceed.2007.02.020

[4] Kane, Y., Lemrabott, A.T., Faye, M., Cissé, M.M., Ka, E.H.F., Niang, A. and Diouf, B. (2017) Apport du GENEXPERT dans le diagnostic de la tuberculose chez les hémodialysés chroniques au sud du Sénégal. Néphrologie \& Thérapeutique, 13, 330. https://doi.org/10.1016/j.nephro.2017.08.146

[5] Mesbahi, T., Jebali, H., Barrah, S., Rais, L., Béji, S., Mami, I., Kheder, R., Krid, M., Smaoui, W., Hamida, F.B., Fatma, L.B. and Zouaghi, M.K. (2018) Démarche diagnostique de la tuberculose chez le dialysé. La Revue de Médecine Interne, 39, A140. https://doi.org/10.1016/j.revmed.2018.03.066

[6] CUEN (2015) Insuffisance rénale chronique et maladie rénale chronique, néphrologie. 6e Edition, ECN, 203-225.

[7] Chrétien, J., Nebut, M. and Danel, C. (1987) Épanchement pleural à fluide clair (à l'exclusion de l'épanchement purulent). Encycl Méd Chir (Paris), 6041, A30.

[8] Sahn, S.A. (1988) The Pleura. American Review of Respiratory Disease, 138, 184-234. https://doi.org/10.1164/ajrccm/138.1.184

[9] Yao, K.H., Bakayoko, A., Henyo, F., Tiemele, E., Selly, C.P., Lou, A.H. and Diallo, D. (2011) Particularités de la tuberculose chez le dialysé chronique Noir africain. Néphrologie \& Thérapeutique, 7, 242-244. https://doi.org/10.1016/j.nephro.2011.01.007

[10] Haddaoui, H., Benamor, J. and Bourkadi, J.E. (2019) Profil étiologique de la pleurésie à l'hôpital Moulay Youssef. Revue des Maladies Respiratoires, 36, A151. https://doi.org/10.1016/j.rmr.2018.10.320

[11] Najah, L., Jabri, H., El Khattabi, W. and Afif, H. (2018) Profil bactériologique de la pleurésie purulente. Revue des Maladies Respiratoires, 37, A151. https://doi.org/10.1016/j.rmr.2018.10.318

[12] El Amrani, M., Asserraji, M., Bahadi, A., El Kabbaj, D. and Benyahia, M. (2016) La tuberculose en hémodialyse. Médecine et Santé Tropicales, 26, 262-266. https://doi.org/10.1684/mst.2016.0569

[13] Steingart, K.R., Schiller, I., Horne, D.J., Pai, M., Boehme, C.C. and Dendukuri, H. 
(2014) Xpert MTB/RIF Assay for Pulmonary Tuberculosis and Rifampicin Resistance in Adults. Cochrane Database of Systematic Reviews, No. 1. Art.N: CD009593. https://doi.org/10.1002/14651858.CD009593.pub3

[14] World Health Organization (2011) Rapid Implementation of the Xpert MTB/RIF Diagnostic Test. Technical and Operational "How-To". Practical Considerations. WHO/HTM/ TB/2011.2. WHO, Geneva, Switzerland. 